\title{
Diagnostic performance of a rapid antigen test for RSV in comparison with a 19-valent multiplex RT-PCR ELISA in children with acute respiratory tract infections
}

Heike Schützle • Josef Weigl • Wolfram Puppe • Johannes Forster $\cdot$ Reinhard Berner

Published online: 2 September 2008

(C) Springer-Verlag 2008

Erratum to: Eur J Pediatr

\section{DOI 10.1007/s00431-007-0581-1}

The last line of the first column of the abstract was rendered incorrectly.

It should read:

For patients $<1$ year the post-test....

The online version of the original article can be found at http://dx.doi. org/10.1007/s00431-007-0581-1.

H. Schützle $\cdot$ R. Berner $(\bowtie)$

Department of Pediatrics and Adolescent Medicine,

University Hospital Freiburg,

Mathildenstr. 1, 79106 Freiburg, Germany

e-mail: reinhard.berner@uniklinik-freiburg.de

J. Weigl - W. Puppe

University Children's Hospital Kiel,

Kiel, Germany

J. Forster

Department of Pediatrics St. Hedwig,

St. Josefs Hospital,

Freiburg, Germany

W. Puppe

University Children's Hospital Mainz,

Mainz, Germany 